\title{
Suplementação de micronutrientes na senescência: implicações nos mecanismos imunológicos
}

\author{
Micronutrients supplementation during the senescence: \\ implications for the immunological functions
}

Maria Rita Carvalho Garbi NOVAES'

Marina Kyomi ITO2

Sandra Fernandes ARRUDA ${ }^{3}$

Polyana RODRIGUES 3

Adriana Queiroz LISBOA ${ }^{3}$

A prevalência de indivíduos idosos em detrimento de indivíduos jovens compreende um quadro comum na população mundial. As estimativas indicam que, em 2050 , cerca de $22 \%$ da população mundial serão constituídos por indivíduos idosos. As mudanças no sistema imune do indivíduo idoso ocorrem acentuadamente na imunidade mediada por células, caracterizada pelo aumento do número de linfócitos T imaturos (CD2+CD3-), decréscimo do número de linfócitos T virgens (CD45RA), aumento dos linfócitos de memória (CD45RO), e aumento das células helper T2, com decréscimo das helper T1. Embora as mudanças na resposta humoral sejam menores no envelhecimento, a menor especificidade e afinidade dos anticorpos nos indivíduos idosos constituem uma diferenciação da resposta imune. Estudos recentes demonstram que no envelhecimento a suplementação de micronutrientes específicos exerce efeitos benéficos sobre o sistema imune.

Termos de indexação: envelhecimento, estado nutricional, micronutrientes, sistema imune.

\section{A B S T R A C T}

The increase of the elderly population is a world-wide common phenomenon. According to some projections, in the year 2050, older people will constitute about $22 \%$ of the world population. Immune system deregulation in aging individuals is mainly a result of changes in cell mediated immunity, characterized by an increased number of immature $T$ lymphocytes (CD2+CD3-), a decrease of $T$ virgin lymphocytes (CD45RA), an increase of

\footnotetext{
1 Faculdade de Medicina, Fundação de Ensino e Pesquisa em Ciências da Saúde. Pós-graduação em Nutrição Humana e Ciências da Saúde, Universidade de Brasília. Campus Universitário Darcy Ribeiro, 70910-900, Brasília, DF, Brasil. Correspondência para/Correspondence to: M.R.C.G. NOVAES. E-mail: <ritanovaes@ig.com.br>.

2 Pós-graduação em Nutrição Humana e Ciências da Saúde, Universidade de Brasília. Brasília, DF, Brasil.

3 Pós-Graduação em Nutrição Humana. Universidade de Brasília. Brasília, DF, Brasil.
} 
memory T lymphocytes (CD45RO), and by an increase in T helper 2 cells associated with a decrease in $T$ helper 1 subset. Although changes in humoral immunity are less accentuated in the aging process, lower affinity for antigens and a narrower spectrum of the antibodies were observed in older people, as a dysfunction of immune response. Recent studies show that, in the aging, the supplementation of specific micronutrients is effective in restoring the normal immune response.

Indexing terms: aging, nutritional status, micronutrients, immune system.

\section{N T R O D U Ç Ã O}

A prevalência de indivíduos idosos em detrimento de indivíduos jovens compreende um quadro comum na população mundial, tanto nas sociedades desenvolvidas quanto nas em desenvolvimento. Embora haja divergências quanto à idade em que os indivíduos passam a ser considerados idosos, a Organização Mundial de Saúde (OMS) considera idoso o indivíduo com idade superior a 65 anos $^{1,2}$. Quando se considera a divisão da população por idade, alguns dados têm chamado atenção para o surgimento de um novo segmento dentro das sociedades: os indivíduos com idade superior a 85 anos $^{3}$.

Tinker ${ }^{1}$ apresenta dados referentes à quantidade de indivíduos idosos no ano de 1999 e às projeções para 2050'. Em 1999, 10\% da população mundial eram compostos por indivíduos idosos, e estima-se que esse número, em 2050, será de $22 \%$. Nos países da América do Sul, estima-se também que, em 2050, 22\% da população serão constituídos de indivíduos idosos, comparados aos 8\% apresentados em 1999.

Esse quadro traz enormes implicações para a sociedade, considerando-se que a senescência está fortemente associada ao aparecimento de doenças infecciosas, crônicas, neurodegenerativas e cardiovasculares. Além das alterações biológicas normais do envelhecimento, o desenvolvimento de tais patologias tem sido associado também ao declínio da resposta imune em indivíduos idosos. Generalizando, o envelhecimento induziria a menores respostas imunes comparadas às observadas em adultos jovens ${ }^{4}$, estando os adultos idosos, portanto, mais suscetíveis a infecções e outras patologias.
A desnutrição energético-protéica e conseqüente deficiência de micronutrientes constituem um problema comum no envelhecimento $^{5}$, que se origina de uma combinação de diferentes fatores, como diminuição do poder socioeconômico nessa idade, isolamento social, síndromes de má absorção e alimentação inadequada ${ }^{6}$.

I MUNIDADE E EN V ELHECIMENTO

\section{Resposta celular}

Estudos clínicos recentes sugerem que as disfunções do sistema imune durante a senescência estariam associadas a uma diferenciação da resposta imune e não ao seu decréscimo irrestrito, como anteriormente descrito ${ }^{4}$. Chandra 7 , em estudo duplo-cego controlado, utilizando indivíduos com idade superior a 65 anos com deficiências nutricionais semelhantes, demonstrou que o grupo de idosos tratados com suplemento multimineral e multivitamímico apresentou resposta imune significativamente maior (número de células T e de NK, produção de IL-2 e atividade de células NK) quando comparado ao grupo placebo, e resposta similar às obtidas em estudos com adultos jovens.

Krause et al. ${ }^{8}$, seguindo os critérios "SENIEUR" de seleção de indivíduos para estudos imunogerontológicos ${ }^{9}$, demonstraram que mulheres sadias idosas (>60 anos) não apresentavam diferenças significativas quanto ao número total de células T, T citotóxicas e The/per no sangue quando comparadas a mulheres adultas 
jovens (20-40 anos). Porém, foram observadas diferenças em relação à proliferação das células Tem resposta ao agente mitótico fitoemaglutinina, sugerindo que alguns tipos de células T específicas podem diminuir em número e/ou em função em indivíduos idosos. Esses resultados sugerem um outro conceito de disfunções específicas da resposta imune associadas à idade, diferente dos trabalhos anteriores, que associavam senescência com decréscimo generalizado no número de células do sistema imune. Tais divergências de conceitos se associam ao fato de alguns estudos adotarem como amostra indivíduos clinicamente saudáveis, sem a realização de exames bioquímicos que avaliassem de forma mais precisa o estado nutricional dos mesmos, especificamente o status de micronutrientes, os quais influenciam, significativamente, o sistema imune. As modificações da resposta imune que ocorrem no envelhecimento estão relacionadas principalmente à imunidade mediada por células $T$ e, de forma mais atenuada, à resposta humoral (células B).

Idosos saudáveis demonstram um decréscimo de $10 \%$ a $15 \%$ na contagem de linfócitos totais. Essa alteração do sistema imune se associa a diferentes fatores, sendo os mais expressivos a diminuição da atividade do timo e a permanente estimulação antigênica ao longo da vida. Entretanto, diferenças significativas são observadas nos diferentes tipos de linfócitos entre os indivíduos idosos e os adultos jovens, ambos com estado nutricional semelhante ${ }^{10}$.

No envelhecimento, observa-se um aumento do número de linfócitos $T$ imaturos (CD2+CD3-) associado ao aumento simultâneo de células NK, um aumento dos linfócitos $T$ de memória (CD45 RO) e um decréscimo do número de linfócitos T virgens (CD45 RA). Outra alteração na resposta imune decorrente do processo de senescência é a mudança na razão entre células Thelper 1 e 2, ocorrendo um aumento nas células T helper 2 (TH2) com simultâneo decréscimo das células T helper 1 (TH1), e aumento da secreção das interleucinas IL4, IL-5 e IL-6 (produtos das células TH2) e decréscimo da secreção da IL-2 (produto das células TH1). Mazari \& Lesourd ${ }^{11}$ avaliaram a resposta do sistema imune de indivíduos adultos jovens (25-34 anos) e idosos (75-84 anos) com estado nutricional distintos: indivíduos normais; indivíduos deficientes em zinco, selênio, folato, $B_{6}, B_{12}$ e indivíduos com hipoalbuminemia. Os resultados mostraram um aumento do número de células imaturas (CD2+CD3-) e diminuição no número de células maduras (CD3+), queda do número de células $T$ virgens (CD45RA) e aumento do número de células de memória (CD45RO), independentemente do estado nutricional nos adultos idosos, quando comparados aos adultos jovens. A diminuição na contagem absoluta de células CD4+ somente foi observada nos indivíduos idosos com alguma deficiência nutricional ${ }^{11}$.

Os trabalhos sugerem que as mudanças que ocorreram no sistema imune de idosos podem ser inerentes ao processo de senescência, e que essas seriam mudanças qualitativas nos tipos celulares, enquanto mudanças quantitativas estariam associadas a indivíduos com comprometimento do estado nutricional. A secreção da interleucina 2 (IL-2) parece estar estreitamente associada ao estado nutricional do indivíduo idoso, sendo produzida em níveis similares quando considerados adultos jovens e idosos que não apresentam deficiência nutricional ${ }^{11}$.

No envelhecimento, o decréscimo da proporção de células virgens em relação às células de memória, e o das células maduras em relação às imaturas está, em parte, associado à involução do timo. Especificamente, ocorre substituição progressiva dos espaços perivasculares por tecido adiposo, restando uma proporção mínima de tecido cortical ou medular ${ }^{12,13}$. As células T virgens remanescentes nos animais idosos são defeituosas, produzem menor nível de IL-2 e, portanto, apresentam menor atividade proliferativa; e ainda têm menor potencial de diferenciação em células efetoras ${ }^{14}$.

\section{Resposta humoral}

No processo de senescência, as mudanças na imunidade humoral se apresentam menores 
quando comparadas à imunidade mediada por células, anteriormente descrita. Durante o envelhecimento há mudanças quantitativas e qualitativas da resposta humoral, sendo observadas alterações do número de imunoglobulinas, do número e atividade das células $B$, assim como mudanças quanto à especificidade $e$ afinidade dos anticorpos ${ }^{15}$.

No envelhecimento humano ocorre um decréscimo na resposta de anticorpos a antígenos específicos, como observado nos casos de vacinas contra a toxina do tétano, anti-influenza e outras. O fato de idosos apresentarem resposta de anticorpos a antígenos estranhos diminuída, quando comparada a de adultos jovens, proporciona a visão de que o envelhecimento levaria a uma imunidade humoral deficiente. No entanto, não existem trabalhos que demonstrem diminuição do número total ou perda das funções das células $B$ e de células $B$ secretoras de imunoglobulinas (lg). Um aumento no número de células B secretoras de anticorpos contra antígenos próprios (auto-antígenos), associado ao decréscimo de anticorpos a antígenos estranhos, sugerem que no envelhecimento ocorra uma mudança na população de células $B$ com relação à especificidade a antígenos, e não um decréscimo generalizado da imunidade humoral ${ }^{15,16}$.

As perdas preferencialmente de $\lg G$ e de anticorpos de alta afinidade durante o envelhecimento contribuem para o aumento da suscetibilidade e severidade de doenças infecciosas, assim como na menor eficiência de vacinas em idosos, uma vez que o $\mathrm{lg} G$ e os anticorpos de alta afinidade oferecem maior proteção contra doenças causadas por bactérias e vírus.

\section{Produção de auto-anticorpos no envelhecimento}

À medida que os organismos vivos entram no processo de envelhecimento, ocorrem mudanças qualitativas na resposta humoral, passando de altamente específica a antígenos estranhos para mais específica a antígenos próprios ${ }^{17}$. Essa perda na capacidade de discriminar os antígenos está associada a um aumento na produção de auto-anticorpos naturais.

Embora organismos idosos tenham maior número de auto-anticorpos, não se pode afirmar que isso reflita manifestações subclínicas de doenças auto-imunes. Auto-anticorpos associados a doenças auto-imunes são antígenos específicos, ao contrário de auto-anticorpos naturais apresentados por organismos idosos que apresentam resposta a uma ampla variedade de antígenos de diferentes tecidos ${ }^{17,18}$.

A alta produção de auto-anticorpos em idosos tem sido associada à menor resistência dessa população a doenças infecciosas. A eficácia da imunização de idosos é significativamente menor quando comparada a de adultos jovens, o que é visualizado pelo menor número de anticorpos produzidos por idosos após imunização. Estudos pioneiros atribuíam a menor produção de anticorpos contra antígenos específicos à involução do timo e menor atividade das células Thelper. No entanto, recentemente, postulou-se a hipótese de que o aumento do número de auto-anticorpos teria também importante influência na deficiente resposta de anticorpos nominais a vacinas.

O aumento do número de auto-anticorpos ocasiona uma queda na produção de células B responsáveis pela secreção de anticorpos a antígenos nominais, o que sugere que indivíduos idosos sejam mais suscetíveis a doenças infecciosas devido a mudanças nos tipos celulares e, conseqüentemente, na população de anticorpos ${ }^{17}$.

Apesar de não estar estabelecido o mecanismo que deflagra a auto-imunidade no processo de senescência, no qual a resposta imune específica está diminuída, uma hipótese seria a reativação de linfócitos de memória. Embora a suplementação nutricional seja efetiva no restabelecimento da resposta imune durante a senescência, vale ressaltar que tal intervenção pode promover uma estimulação não exclusivamente de células virgens, mas a ativação das 
células de memória, intensificando a autoreatividade, principalmente em indivíduos idosos sem deficiências nutricionais.

\section{MICRONUTRIENTES ANTIOXIDANTES E I MUNIDADE}

O estado nutricional tem um papel crucial na manutenção da função imune independente da idade 8,19,20. É observado um declínio na função imunológica, independente do sexo, a partir de, aproximadamente, 50 anos de idade, com conseqüências no envelhecimento ${ }^{5,21}$.

A disfunção imune relacionada à idade pode ser particularmente prevenida ou retardada por intervenção dietética ${ }^{5,22}$. O declínio em ambos os parâmetros específicos e não específicos da imunidade tem sido associado à desnutrição e à deficiência de proteína. Tem-se especulado que esse declínio contribui para o aumento da mortalidade em idosos, especialmente quando relacionada ao câncer e a doenças infecciosas .

As deficiências de alguns elementos traços e de vitaminas também podem estar associadas ao decréscimo na função imune $e^{4,11,23}$. Recentes progressos na compreensão do mecanismo de ação de antioxidantes no metabolismo celular têm mostrado que os micronutrientes antioxidantes podem modular fatores de sinais de transdução, transcrevendo genes envolvendo células imunomediadas e produção de citocinas ${ }^{22}$.

\section{Suplementação de micronutrientes antioxidantes no envelhecimento}

Tem sido observado que, na população idosa, a suplementação de alguns micronutrientes melhora alguns aspectos da função imune (Tabela 1), como resposta proliferativa linfocitária e função das células NK, produção de IL-2 e resposta humoral após vacinação 19,21,24.

Devido à relativa raridade de deficiência da vitamina E em idosos humanos, existem poucos estudos nessa área. Entretanto, estudos em animais com deficiência em vitamina $E$ têm demonstrado uma depressão na proliferação linfocitária em coelhos, porcos, galinhas e cachorro. Um estudo de caso mostrou a deficiência de vitamina E em uma mulher de 59 anos em conseqüência de má absorção intestinal, causando um prejuízo na função mediada por células $T$, mediadas com células $T$ para Con $A$, níveis IL-2 e atraso no teste de hipersensibilidade (DTH). A paciente foi tratada com acetato $\alpha$-tocoferol oral (100Ul/dia) por três meses, seguido por injeção de $\alpha$-tocoferol (50mg i.m.) diariamente por cinco dias, e por injeção de manutenção três vezes por semana. Após administração da vitamina $E$, o aumento dos níveis de $\alpha$-tocoferol no plasma correlacionou-se com uma melhor resposta da proliferação da célula $T$ para mitogênese, produção de IL-2 e também o DTH. Porém, devido ao limitado número de estudos, é possível especular que a deficiência de vitamina E em humanos pode estar associada ao prejuízo de células imune mediada, um co-fator no desenvolvimento de algumas doenças ${ }^{22}$.

Para investigar o efeito de longo período de suplementação e ótimos níveis de suplementação de vitamina E na função imune, Meydani et al. ${ }^{25}$ conduziram um estudo em idosos não institucionalizados que receberam um dos seguintes tratamentos: placebo, 60, 200 ou $800 \mathrm{mg} /$ dia de vitamina $\mathrm{E}$ (Tabela 1). Os níveis de vitamina $\mathrm{E}$ aumentaram significativamente, de forma dose-dependente, de acordo com o grupo tratado: $38,5 \pm 5,3 \mu \mathrm{mol} / \mathrm{L}, 51,0 \pm 13,6 \mu \mathrm{mol} / \mathrm{L}$, $71,5 \pm 26,5 \mu \mathrm{mol} / \mathrm{L}$, respectivamente. Ao final da suplementação, todos os grupos que receberam vitamina $\mathrm{E}$ apresentaram um aumento na resposta de DTH, sendo observado um aumento significativamente maior no grupo que recebeu $200 \mathrm{mg}$ de vitamina E por dia. Os sujeitos desse grupo também apresentaram um aumento nos anticorpos para hepatite B e tétano. Com esses resultados os autores sugerem que uma suplementação de $200 \mathrm{mg}$ de vitamina E por dia representa eficiente resposta imune, com possível efeito imunoestimulador ocasionado pela vitamina $\mathrm{E}$; mas os autores afirmam que essa hipótese necessita de mais investigações ${ }^{25}$. 
Tabela 1. Suplementação nutricional de micronutrientes (antioxidantes) e resposta imune em indivíduos idosos - estudos clínicos.

\begin{tabular}{|c|c|c|c|c|c|c|}
\hline Tipo de estudo & Amostra & Sexo/idade & Período(meses) & $\begin{array}{c}\text { Suplementação } \\
\text { (nutriente/dosagem) }\end{array}$ & Principais resultados & Referências \\
\hline $\begin{array}{l}\text { Estudo clínico } \\
\text { duplo-cego } \\
\text { placebo controle }\end{array}$ & 32 & $\begin{array}{c}\text { ambos } \\
\geq 60 \text { anos }\end{array}$ & 1,0 & dl- $\alpha$-tocoferol - 800mg & $\begin{array}{l}\uparrow \text { resposta DTH } \\
\uparrow \text { resposta mitogênica in } \\
\text { vitro } \\
\downarrow \text { produção de PGE2 } \\
\downarrow \text { peroxidação lipídica no } \\
\quad \text { plasma } \\
\uparrow \text { IL-2; } \uparrow \text { proliferação } \\
\text { linfocitária }\end{array}$ & Meydani et al. ${ }^{26}$ \\
\hline $\begin{array}{l}\text { Randomizado, } \\
\text { duplo-cego, } \\
\text { placebo controle }\end{array}$ & 88 & $\begin{array}{c}\text { ambos } \\
\geq 65 \text { anos }\end{array}$ & 4,5 & $\begin{array}{l}\text { Vitamina E - Placebo, } \\
60,200^{1} \text { e } 800 \mathrm{mg}\end{array}$ & $\begin{array}{l}\uparrow \text { vitamina E plasmática } \\
\uparrow \text { resposta DTH } \\
\uparrow \text { anticorpos titer para } \\
\text { hepatite B e tétano não } \\
\text { foi observado alteração } \\
\text { níveis de auto-anticorpos. }\end{array}$ & Meydani et al. ${ }^{25}$ \\
\hline $\begin{array}{l}\text { Intervenção } \\
\text { Duplocego } \\
\text { Placebo-controle }\end{array}$ & 52 & $\begin{array}{l}\text { ambos } \\
67-85 \text { anos }\end{array}$ & 3,0 & dl- $\alpha$-tocoferol -100mg & $\begin{array}{l}\uparrow \text { vitamina E plasmática } \\
\leftrightarrow \text { resposta proliferativa } \\
\text { linfócitos } \\
\leftrightarrow \text { concentração de } \\
\text { anticorpos para } \\
\text { antígenos conhecidos }\end{array}$ & De Waart et al. ${ }^{27}$ \\
\hline $\begin{array}{l}\text { Ensaio duplo-cego } \\
\text { Placebo controle }\end{array}$ & yo 161 & $\begin{array}{c}\text { ambos } \\
65-80 \text { anos }\end{array}$ & 6,0 & $\begin{array}{l}\text { dl- } \alpha \text {-tocoferol - } \\
50 \mathrm{mg} 100 \mathrm{mg}\end{array}$ & $\begin{array}{l}\uparrow \text { resposta DTH } \\
\uparrow \mathrm{IL}-2 ; \uparrow \mathrm{IL}-4 ; \uparrow \text { IFN- } \gamma \\
\quad \text { (tendência, grupo 100mg) }\end{array}$ & Pallast et al. ${ }^{28}$ \\
\hline Ensaio-clínico & 30 & $\begin{array}{c}\text { O } \\
70-82 \text { anos }\end{array}$ & 0,5 & $\begin{array}{l}\alpha \text {-tocoferol - 200mg } \\
\text { ácido ascórbico - } 1 \mathrm{~g}\end{array}$ & $\begin{array}{l}\downarrow \text { peroxidação lipídica e } \\
\text { produção de superóxidos } \\
\uparrow \text { capacidade de quimiotaxia } \\
\uparrow \text { proliferação linfocitária } \\
\uparrow \text { capacidade fagocitária }\end{array}$ & De La Fuente et al. ${ }^{29}$ \\
\hline $\begin{array}{l}\text { Ensaio-clínico } \\
\text { Randomizado, } \\
\text { duplo-cego }\end{array}$ & 725 & $\begin{array}{l}\text { ambos } \\
\text { 65-103 anos }\end{array}$ & 24,0 & $\begin{array}{l}\text { Grupo } \mathrm{T}^{2} \text { - Sulfato de } \\
\text { Zn e Sulfato de Se ( } 20 \\
\text { mg e } 100 \mu \mathrm{g} \text {, respecti- } \\
\text { vamente). } \\
\text { Grupo } \mathrm{V}^{2} \text { - Vit C ( } 120 \\
\mathrm{mg}) \text {, beta-caroteno } \\
\text { (6mg) e alfa-tocoferol } \\
\text { (15 mg) } \\
\text { Grupo VT2 - com vita- } \\
\text { mina e elementos tra- } \\
\text { ços. Grupo } \mathrm{P}^{2} \text { - placebo }\end{array}$ & $\begin{array}{l}\downarrow \text { da deficiência de nutrien- } \\
\text { tes nos respectivos gru- } \\
\text { pos } \\
\text { Se e Zn } \uparrow \text { resposta de } \\
\text { anticorpos após FLU vaci- } \\
\text { na e } \uparrow \% \text { de sujeitos sem } \\
\text { infecção do trato respira- } \\
\text { tório. }\end{array}$ & Girodon et al. ${ }^{21}$ \\
\hline
\end{tabular}

1 o melhor resultado foi do grupo que recebeu $200 \mathrm{mg} ;{ }^{2} \mathrm{~T}=$ elementos traços; $\mathrm{V}=$ vitamina; $\mathrm{VT}=$ vitamina e elementos traços; $\mathrm{P}=$ placebo; FLU = influenza $\uparrow$ aumento; $\downarrow$ diminuição; $\leftrightarrow$ sem alteração.

De Waart et al. ${ }^{27}$, porém, não obtiveram os mesmos resultados favoráveis encontrados nos estudos de Serafini ${ }^{22}$ e Meydani et al. ${ }^{25}$. O aumento da vitamina E plasmática no estudo de de Waart et al. ${ }^{27}$, apesar de significante, foi muito pequeno $(+16,7 \%)$, não proporcionando uma melhora na resposta imune dos indivíduos quando comparado ao estudo de Meydani et al. ${ }^{25}$, no qual os valores apresentaram-se triplicados.

Apesar dos resultados pouco significantes encontrados por Pallast et al. ${ }^{28}$, foi observado que idosos aparentemente saudáveis, mas com baixa 
resposta para o teste de hipersensibilidade ou sedentários, apresentaram melhores respostas no teste de hipersensibilidade após seis meses de suplementação com 100mg de vitamina E, quando comparados aos submetidos ao placebo.

Em um estudo realizado por Girodon et al. ${ }^{21}$, em idosos institucionalizados e aparentemente saudáveis, o uso de suplementação que continha elementos traço de zinco e selênio (associado ou não a vitaminas) promoveu melhor resposta humoral após vacinação contra o vírus influenza e menor incidência de infecção do trato respiratório. As melhores respostas foram encontradas no grupo suplementado apenas com elementos traço (Tabela 1).

Os autores sugerem duas possíveis explicações para a influência do zinco na resposta humoral. A primeira hipótese sugere a restauração da atividade do hormônio timulina, que requer a presença de zinco para se expressar e está envolvido na proliferação timocítica, e a resposta para a vacina influenza é linfócito $T$ dependente. A segunda estaria relacionada à melhora do estado nutricional, que apresenta estreita relação com o sistema imunológico ${ }^{20}$. Em um estudo em que foi suplementado zinco por oito semanas em idosos hospitalizados, foi observada melhora da ingestão alimentar e dos níveis séricos de albumina ${ }^{30}$.

O zinco é importante nas atividades de enzimas, peptídeos, fatores de transdução de sinal e de citocina, envolvidas em vários passos fisiológicos do desenvolvimento e reatividade imune $^{31}$.

\section{Micronutrientes e resposta imune no envelhecimento}

Algumas mudanças funcionais ligadas à nutrição que ocorrem na senescência impedem que os idosos tenham uma ingestão alimentar adequada e, por conseguinte, de micronutrientes. São observados um decréscimo significativo na sensibilidade ao gosto de doce e salgado e o uso freqüente de medicamentos que podem afetar a acuidade do paladar e provocar sensação de secura na boca ${ }^{32}$.

Em estudo realizado por Kemp et al. ${ }^{19}$, foi demonstrado que aproximadamente $90,0 \%$ dos idosos estudados apresentaram ingestão alimentar abaixo das DRI para vitamina $B_{12}$ e folato, enquanto para vitamina $B_{6}$ e zinco em torno de $50,0 \%$ apresentaram ingestão inadequada $\left(\mathrm{B}_{6}-50,0 \%\right.$; Zn - 29,0\% para homens, 66,7\% para mulheres).

A falta de ingestão de micronutrientes implica em deficiências que afetam a resposta imune mediada em idosos ${ }^{24}$.

Raviaglia et al. ${ }^{24}$ mostram que a função imune mediada pelas células NK de sujeitos com idade superior a 90 anos foi associada positivamente com níveis séricos de zinco e selênio, deficiência que é muito comum nessa idade. $O$ mesmo estudo observou deficiência desses minerais em torno de $50 \%$ (Tabela 2). Vale ressaltar que os sujeitos recrutados para essa pesquisa eram aparentemente saudáveis, porém apresentavam deficiência de vitamina $B_{6^{\prime}}$ além desses elementos traços, mostrando que não se deve descartar a possibilidade de deficiência de micronutrientes em idosos aparentemente saudáveis ${ }^{33}$. Alguns estudos em humanos e animais mostram um decréscimo na atividade das células NK durante o estado de deficiência de zinco.

Também foi observado neste estudo uma correlação positiva entre a atividade citolítica das células NK e vitamina E. Apesar de os mecanismos do efeito imunoestimulatório da vitamina $E$ continuarem desconhecidos, há evidências de que a vitamina $E$ pode exercer esse efeito pela regulação na síntese de prostaglandinas, diminuição da formação de radicais livres ou ambos.

Num estudo realizado por Kemp et al. ${ }^{19}$, observa-se que houve pouca associação entre o teste de hipersensiblidade cutânea e níveis séricos de micronutrientes. Foi observada deficiência dos 
micronutrientes analisados entre os idosos. Houve associação positiva entre a IL-2 e $\beta$-caroteno e vitamina $B_{6}$ (Tabela 2 ). Todavia na análise de regressão múltipla, somente a vitamina $B_{6}$ foi associada.

Gardner et al..$^{34}$ observaram um aumento sérico de $\beta$-caroteno e tocoferol em idosos, sem nenhuma correlação entre $\beta$-caroteno, retinol, $\alpha$-tocoferol, zinco e resposta de anticorpos após a imunização com vacina de influenza. Os níveis plasmáticos para quatro micronutrientes foram normais entre os indivíduos. O aumento plasmático de $\beta$-caroteno e tocoferol nos idosos poderia induzir uma melhor resposta celular e humoral para vacina da influenza. Porém, os idosos com níveis sangüíneos de micronutrientes dentro dos

Tabela 2. Dosagem sérica de micronutrientes e resposta imune em indivíduos idosos.

\begin{tabular}{|c|c|c|c|c|}
\hline $\begin{array}{l}\text { Tipo de estudo } \\
\text { Autores }\end{array}$ & Amostragem & $\begin{array}{c}\text { Micronutrientes } \\
\text { dosados }\end{array}$ & Resposta imune & Principais resultados \\
\hline Ravaglia, G et al. ${ }^{24}$ & $\begin{array}{l}62 \text { idosos (>90anos) } \\
17 \text { jovens-controle } \\
\text { (21-38 anos) }\end{array}$ & $\begin{array}{l}\text { Retinol, } \alpha \text {-tocoferol; } \\
\text { Se, } Z n \text {, folato, } \\
\text { vitamina } B_{12^{\prime}} \\
\text { piridoxal-5-fosfato } \\
\left(B_{6}\right)\end{array}$ & Atividade das células NK & $\begin{array}{l}\text { Deficiência em torno de } \\
50 \% \text { da amostra de Se, } \\
\text { Zn e Vit B6. } \\
\text { Correlação +: } \\
\text { - Zn e NK } \\
\text { - Selênio e um tipo de } \\
\text { NK (CD16+) } \\
\text { - Vitamina E e atividade } \\
\text { citolítica das células NK.* } \\
\text { Nenhuma correlação dos } \\
\text { nutrientes com outras } \\
\text { células. }\end{array}$ \\
\hline $\begin{array}{l}\text { Krause et al. }{ }^{8} \\
\text { Coorte }\end{array}$ & $\begin{array}{l}44 \text { idosos (>60 anos) } \\
26 \text { jovens ( } 20-40 \\
\text { anos) mulheres. }\end{array}$ & $\begin{array}{l}\text { Vitamina } B_{12} \text {, ácido } \\
\text { fólico }\end{array}$ & $\begin{array}{l}\text { Declínio da função } \\
\text { imune }\end{array}$ & $\begin{array}{l}\leftrightarrow \text { vitamina } B_{12} \text {, ácido fólico } \\
\text { entre ambos grupos }\end{array}$ \\
\hline Gardner et al. ${ }^{34}$ & $\begin{array}{l}61 \text { idosos }(70-95) \\
27 \text { jovens }(23-38)\end{array}$ & $\begin{array}{l}\beta \text {-caroteno, retinol, } \\
\alpha \text {-tocoferol e zinco }\end{array}$ & $\begin{array}{l}\text { Resposta imune após } \\
\text { imunização com FLU } \\
\text { vacina. }\end{array}$ & $\begin{array}{l}\uparrow \beta \text {-caroteno } \uparrow \alpha \text {-tocoferol } \\
\text { em pessoas idosas tanto } \\
\text { antes quanto após imuni- } \\
\text { zação } \\
\text { nenhuma correlação entre } \\
\beta \text {-caroteno, retinol, } \alpha \text {-tocoferol } \\
\text { e zinco e resposta de anticor- } \\
\text { pos após vacinação FLU. }\end{array}$ \\
\hline $\begin{array}{l}\text { Fata et al. }{ }^{35} \\
\text { Coorte }\end{array}$ & $\begin{array}{l}15 \text { idosos (> } 65 \text { anos) } \\
\text { com baixos níveis de } \\
\text { vitamina } B_{12} \text { sérica e } 15 \\
\text { idosos pareados quan- } \\
\text { to a idade e diagnós- } \\
\text { tico com níveis normais }\end{array}$ & Vitamina $\mathrm{B}_{12}$ & $\begin{array}{l}\text { Resposta de anticorpos } \\
\text { após imunização com } \\
12 \text { sorotipos de } \\
\text { pneumococos }\end{array}$ & $\begin{array}{l}\text { Pacientes com baixos níveis } \\
\text { de vitamina } B_{12} \text { sérica tive- } \\
\text { ram menor resposta de } \\
\text { anticorpos que o controle. }\end{array}$ \\
\hline $\begin{array}{l}\text { Kemp et al. }{ }^{19} \\
\text { Transversal }\end{array}$ & $\begin{array}{l}65 \text { idosos }(53-86 \\
\text { anos) }\end{array}$ & $\begin{array}{l}\text { Vitaminas } B_{6}, B_{12}, C, \\
\beta \text {-caroteno, } \alpha \text { e } \gamma \\
\text { tocoferol, retinol, } \\
\text { zinco }\end{array}$ & $\begin{array}{l}\text { Relação do sistema } \\
\text { imune: DTSH, IL-2R } \\
\text { com micronutrientes } \\
\text { séricos }\end{array}$ & $\begin{array}{l}\text { Pouca associação entre } \\
\text { DTSH e micronutrientes } \\
\text { séricos, } \\
\text { + associação entre IL-2R e } \\
\text { vitamina } B_{6} \\
\text { - associação entre IL-2R e } \\
\beta \text {-caroteno }\end{array}$ \\
\hline
\end{tabular}

*ajustado lipídio; resultados achados para o sexo feminino; $\uparrow$ aumento; $\leftrightarrow$ sem alteração. 
padrões de normalidade continuam tendo resposta similar aos indivíduos jovens.

O estudo de Fata et al. ${ }^{35}$ sugere que quando os indivíduos idosos têm deficiência de vitamina $B_{12}$ há menor resposta humoral após imunização com doze sorotipos de pneumococos comparados com grupo controle.

Krause et al. ${ }^{8}$ mostraram que mulheres idosas sem sinais de deficiência de vitamina $B_{12} e$ ácido fólico têm resposta imunológica similar às mulheres jovens, indicando que, se o estado nutricional for mantido, a imunocompetência é preservada.

\section{O N CLUSÃ O}

A redução da resposta imune em idosos está fortemente associada a deficiências nutricionais, não constituindo uma resposta biológica generalizada associada ao processo de envelhecimento. Diversos estudos demonstram que o estado nutricional do indivíduo idoso está diretamente relacionado à imunocompetência do organismo durante o processo de senescência, constituindo, dessa forma, os programas de avaliação e intervenção sobre o estado nutricional ferramentas importantes na promoção da saúde em idosos.

No entanto, a utilização de quantidades suplementares de micronutrientes, assim como a administração de suplementos a indivíduos idosos que não apresentem deficiências nutricionais, devem ser reavaliadas considerando-se possíveis efeitos deletérios dessa terapia sobre as disfunções do sistema imune na senescência. Tais pesquisas se tornam importantes uma vez que, qualquer intervenção que tenha por objetivo estimular a resposta imune em organismos idosos, deve ser seletiva ao estimular a produção de células virgens e células de memória recente e sem reativar as células de memória geradas ao longo da vida, algumas das quais poderiam gerar um processo auto-reativo.
Dessa forma, o monitoramento nutricional do idoso deve ser priorizado, visando prevenir ou identificar precocemente possíveis deficiências nutricionais e revertê-las com o uso de suplementação em dosagens adequadas a fim de minimizar os possíveis efeitos deletérios da senescência relacionados à imunidade, como o câncer e as doenças infecciosas.

\section{REFER Ê N CIAS}

1. Tinker $A$. The social implications of an aging population. Mech Aging Dev. 2002; 123(7): 729-35.

2. Goyns MH. The biology of aging. Mech Aging Dev. 2002; 123:727.

3. Duthie Jr EH, Katz PR. História e exame físico. 3. ed. In: Duthie Jr EH. Geriatria prática. Rio de Janeiro: Revinter; 2002.

4. Lesourd BM. Nutrition and immunity in the elderly: modification of immune responses with nutritional treatments. Am J Clin Nutr. 1997; 66(2):S478-84.

5. High KP. Micronutrient supplementation and immune function in the elderly. Clin Infect Dis. 1999; 28(4):717-22.

6. Beaumont $D$, Lehmann AB, James OFW. Protein turnover in malnourished elderly subjects: the effects of referring. Age Ageing. 1989; 18(4): 235-40.

7. Chandra RK. Effect of vitamin and trace-element supplementation on immune responses and infection in elderly subjects. Lancet. 1992; 340(8828):1124-7.

8. Krause D, Mastro AM, Handte G, Smiciklas-Wright $\mathrm{H}$, Miles MP, Ahluwalia N. Immune function did not decline with aging in apparently healthy, well-nourished women. Mech Ageing Dev. 1999; 112(1):43-57.

9. Ligthart GJ, Corberand JX, Fournier C, Galanaud P, Hijmans W, Kennes B, et al. Admission criteria for immunogerontological studies in man: the SENIEUR protocol. Mech Ageing Dev. 1984; 28(1):47-55.

10. Lesourd BM, Meaume S. Cell mediated immunity changes in ageing, relative importance of cell subpopulation switches and of nutritional factors. Immunol Lett. 1994; 40(30):235-42.

11. Mazari L, Lesourd BM. Nutritional influences on immune response in health aged persons. Mech Ageing Dev. 1998; 104(1):25-40. 
12. Douek DC, Koup RA. Evidence for thymic function in the elderly. Vaccine. 2000; 18(16):1638-41.

13. Beverley PC, Grubeck-Loebenstein B. Is immune senescence reversible? Vaccine. 2000; 18(16): 1721-4.

14. Stacy S, Krolick KA, Infante AJ, Kraig E. Immunological memory and late onset autoimmunity. Mech Ageing Dev. 2002; 123(8):975-85.

15. Weksler ME. Changes in the B-cell repertoire with age. Vaccine. 2000; 18(16):1624-8.

16. Zhao KS, Wang YF, Gueret R, Weksler ME. Dysregulation of the humoral immune response in old mice. Int Immunol. 1995; 7(6):929-34.

17. Weksler ME, Goodhardt M. Do age-associated changes in "physiologic" autoantibodies contribute to infection, atherosclerosis, and Alzheimer's disease? Exp Geront. 2002; 37(8-9): 971-9.

18. Nobrega A, Haury M, Gueret R, Coutinho A, Weksler ME. The age associated increase in autoreactive immunoglobulins reflects a quantitative increase in specifities detectable at lower concentrations in young mice. Scand J Immunol. 1996; 44(5):437-43.

19. Kemp FW, DeCandia J, Li W, Bruening K, Baker H, Rigassio $D$, et al. Relationships between immunity and dietary and serum antioxidants, trace metals, $B$ vitamins, and homocysteine in elderly men and women. Nutr Res. 2002; 22:45-53.

20. Fraker JP, King LE, Laakko T, Vollmer TL. The dynamic link between the integrity of the immune system and zinc status. J Nutr. 2000; 130(5S Suppl):S1399406.

21. Girodon F, Galan P, Monget A, Boutron-Ruault M, Brune-Lecomte $P$, Preziosi $P$, et al. Impact of trace elements and vitamin supplementation on immunity and infections in institutionalized patients: a randomized controlled trial. Arch Intern Med. 1999; 159(7):748-54.

22. Serafini M. Dietary vitamin E and T cell-mediated function in the elderly: effectiveness and mechanism of action. Int J Neurosc. 2000; 18 (4-5):401-10

23. Chandra RK. Nutrition and the immune system: an introduction. Am J Clin Nutr. 1997; 66(2): S460-3.

24. Ravaglia G, Forti P, Mioli F, Bastagli L, Facchini A, Savarino $L$, et al. Effect of micronutrient status on natural killer cell imune function in healthy free-living subjects aged $\geq 90 \mathrm{y}$. Am J Clin Nutr. 2000; 71(2):590-8.
25. Meydani SN, Meydani M, Blumberg JB, Leka LS, Siber G, Loszewski R, et al. Vitamin $E$ supplementation and in vivo immune response in healthy elderly subjects: a randomized controlled trial. JAMA. 1997; 277(7):1380-6.

26. Meydani SN, Barklund PM, Liu S, Meydani M, Miller RA, Cannon JC, et al. Vitamin E supplementation enhances cell-mediated immunity in healthy elderly subjects. Am J Clin Nutr. 1990; 52(3):557-63.

27. De Waart FG, Portengen L, Doekes G, Verwaal DJ, Kok FJ. Effect of 3 months vitamin $E$ supplementation on indices of the cellular and humoral immune response in elderly subjects. $\mathrm{Br} \mathrm{J}$ Nutr. 1997; 78(5):761-74.

28. Pallast EG, Schouten EG, Waart FG, Fonk HC, Doekes $G$, Mary von Blomberg B, et al. Effect of 50- and 100-mg vitamin E supplements on cellular immune function in no institutionalized elderly persons. Am J Clin Nutr. 1999; 69(6):1273-81.

29. De la Fuente $M$, Ferrández MD, Burgos MS, Soler A, Prieto A, Miquel J. Immune function in aged women is improved by ingestion of vitamins $C$ and E. Can J Physiol Pharmacol. 1998; 76(4): 373-80.

30. Boukaiba N, Flament C, Acher S. A physiological amount of zinc supplementation: effects on nutritional, lipid, and thymic status in an elderly population. Am J Clin Nutr. 1993; 57(4):566-72.

31. Mocchegiani E, Muzzioli M, Giacconi R. Zinc and immunoresistance to infection in aging: new biological tools. Trends Pharmacol Sci. 2000; 21(6):205-8.

32.FUNCOR. Alimentação na terceira idade. Rev Nutrição. 2002; 1(14):28-30.

33. Shankar AH, Prasad AS. Zinc and immune fuction: the biological basis of altered resistance to infection. Am J Clin Nutr. 1998; 68(2 Suppl): S447-63.

34. Gardner EM, Bernstein ED, Popoff KA, Abrutyn $E$, Gross P, Murasko DM. Immune response to influenza vaccine in healthy elderly: lack of association with plasma $\beta$-carotene, retinol, $\alpha$-tocopherol, or zinc. Mech Ageing Dev. 2000; 117(1-3):29-45.

35. Fata FT, Herzlich BC, Schiffman G, Ast AL. Impaired antibody responses to pneumococcal polysaccharide in elderly patients with low serum vitamin B sub 12 levels. Ann Int Med. 1996; 124(3): 299-304.

Recebido para publicação em 19 de dezembro de 2003 e aceito em 18 de maio de 2004. 